EESTI NSV TEADUSTE AKADEEMIA TOIMETISED. VII KOIDE

BIOLOOGILINE SEERIA. 1958, NR. 1

ИЗВЕСТИЯ АКАДЕМИИ НАУК ЭСТОНСКОИ ССР. ТОМ VII

СЕРИЯ БНОЛОГИЧЕСКАЯ. 1958, 스 1

\title{
ANDMEID EESTI VESIKIRBULISTE (CLADOCERA) FAUNAST
}

\section{A. Mäemets}

Käesoleva artikli eesmärgiks on uute materjalide lisamisega täiendada meie teadmisi Eesti vesikirbuliste fauna koosseisu, liikide ökoloogia ja geograafilise leviku kohta.

Vanimaid andmeid Eesti vesikirbuliste kohta leidub Audova (1923), Brauni (1884), Grube (1853), Levanderi $(1908,1920)$, Mühleni (1908), Riikoja (1923, 1925, 1928, 1929. 1931), Samsonovi $(1906,1908,1912,1913)$ ja Taube (1911) töödes. Enamasti on need andmed laiali paisatud mitmesugustes järvede ja mere planktonit käsitlevates töödes. Vesikirbuliste spetsiaalse uurimuse autoriks on J. Lepiksaar (1932), kes vōttis kokku varasemad andmed ja käsitles lisaks järvedele esmakordselt ka lompide ning teiste väikeveekogude faunat. 25 aastat tagasi ilmunud Lepiksaare töös on ilma igasuguste ökoloogiliste andmeteta esitatud $68^{1}$ (autori enda järgi 70) vesikirbulise liigi loend. Viimasel kahel aastakümnel on lisandunud veelgi andmeid rea järvede (Vinkel, 1934; Riikoja, 19442; Schönberg, $1957^{3}$ ) ja väikeveekogude (Mikelsaar, 1933) ning Emajōe (Sepp, 1950; Lumberg. 1956) ja Soome lahe (Schönberg, 1950) vesikirbuliste fauna kohta, millele on väärtuslikuks täienduseks ka aastail 1951-1957 ENSV TA Zooloogia ja Botaanika Instituudi järvede ekspeditsioonil kogutud zooplanktoni materjal (umbes 200-st järvest). Selle materjali, eriti vesikirbuliste osas, on käesoleva artikli autor läbi töötanud koos 1955. aastast peale kogutud materjaliga meie väikeveekogude, jõgede, ojade ja mere vesikirbuliste kohta. Lisaks nimetatud materjalile on autor kasutanud ka teiste uurijate kogutud zooplanktoni proove, mille kohta kirjanduses andmeid pole avaldatud, nagu R. Voore (Vinkel) proovid reast Eesti järvedest ja jōgedest (Narva jōgi, Pärnu jõgi) aastatel 1933-1943; Samsonovi proovid Peipsi ja Pihkva järvest aastal 1909; Bome'i proovid Narva jōe vesikonnast aastal 1922 (Samsonovi ja Bome'i proovid on saadud prof. Riikojalt).

Territoriaalselt on läbi uuritud kogu Eesti NSV ala (joon. 1), kusjuures kōige pōhjalikumalt on uuritud meie järvede, vähemal määral väikeveekogude ja vooluvete vesikirbulisi. Käesolev artikkel on koostatud 978 proovi põhjal, mis pärinevad 348-st veekogust.

\section{Eesti NSV-s leiduvate vesikirbuliste fauna zoogeograafiline analüüs}

Seniste uurimiste tulemusena on Eesti faunas leitud 79 liiki vesikirbulisi, millest 75 osutusid magevee- ja 4 mereliigiks. Neist 9 liiki on autor esitanud esmasleidudena Eesti NSV-le. ${ }^{4}$ Nimetatutele võiks veel lisanduda 5 liiki, keda on leitud meie naaberaladelt: Camptocercus fennicus Stenroos, Alonopsis ambigua Lillj., Alona karelica Stenroos, Pleuroxus striatus Schoedler ja Chydorus pigroides Lillj.

Jälgides Eesti vesikirbuliste fauna koosseisu kuuluvate likide levikut zoogeograafilistes regioonides ${ }^{5}$ selgub, et meie 79 liigist esineb 12 liiki $(15,2 \%)$ ainult Palearktises, kuna teised liigid levivad ka väljaspool Palearktise piire. Nii on holarktilisi liike $27(34,2 \%)$, kuna 40 liiki $(50,6 \%)$ levib peale Holarktise ka teistes regioonides, kusjuures kosmopoliite on 12 liiki $(15,2 \%)$. Palearktise liikidest on Bosmina coregoni pelagiaali alamliigid (coregoni-rida) ja Bythotrephes longimanus subsp. balticus (Ischr.) nähtavasti Balti endeemikud.

1 Käesolevas artiklis kasutatud süsteemi jărgi. 1944.

${ }^{2} \mathrm{R}$ i i k oj a, H., Ưlevaade planktonorganismide esinemisest Eesti järvedes. Käsikiri.

${ }^{3}$ Ш е н берг Н. Н., Данные о кормовой базе и питанин планктоноядных рыб озера Выртсярв. Käsikiri ENSV TA Zooloogia ja Botaanika Instituudis. 1957.

4 Liikide loetelus märgitud tärnikesega.

5 Tuleb arvestada, et esitatud andmed on kahtlemata ligikaudsed, sest vesikirbuliste geograafilist levikut maakera ulatuses on veel suhteliselt vähe uuritud. 


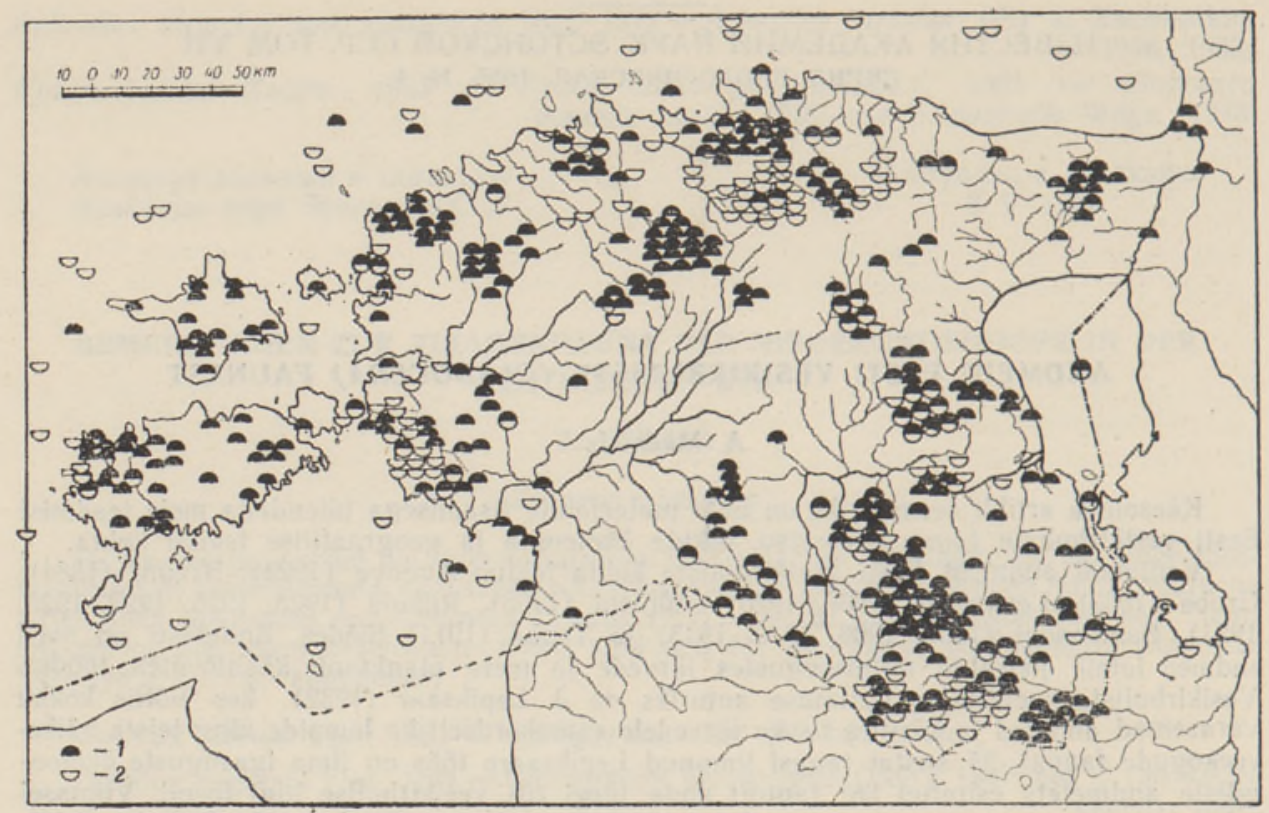

Joon. 1. Vesikirbuliste suhtes läbiuuritud Eesti veekogude geograafiline levik: $I$ - käesoleva kirjutise autori poolt uuritud veekogud, 2 - varasemate autorite poolt uuritud veekogud.

Esitatud arvud erinevad tublisti Eesti mardikaliste ja kõrgemate taimede biogeograafilise analüüsi (Haberman, 1956; Lippmaa, 1935) tulemustest. Nii on Habermani andmeil $81 \%$ meie mardikaliste liikidest puhtpalearktilise levikuga, kuna kōrgemate taimede suhtes on Lippmaa saanud analoogilise tulemuse. Kahtlemata sōltuvad need erinevused vesikirbuliste väga suurest passiivse levimise võimest ning paljude liikide ulatuslikust ökoloogilisest valentsist. Kui eraldada Behningi (1941) eeskujul ka väljaspool Palearktist levivate liikide hulgast Palearktisele iseloomulikumad pōhiliselt siin levivad liigid (meie liikidest 53) ja lisada neile puhtpalearktilised, saame Palearktisele iseloomulikke liike $65(82,3 \%)$.

Vaadeldes Eestis esinevate vesikirbuliste levikut kliimavöötmete suhtes selgub, et boreaalseid liike ${ }^{1}$ on $14^{2}(17,7 \%)$, kuna boreotroopilisi liike ${ }^{3}$ on $65(82,3 \%)$.

Boreaalse Bosmina coregoni subsp. obtusirostris'e vormi f. arctica't tuleb Rõlovi (1940) järgi pidada arktiliseks (tundra) elemendiks.

Taiga elementideks on Limnosida frontosa, Ophryoxus gracilis, kuid nähtavasti ka Daphnia cristata, Scapholeberis microcephala, Drepanothrix dentata ja Bythotrephes cederstoemi, kuigi $D$. cristata ja $D$. dentata levivad veidi kaugemale lōunasse. Segametsade vööndi elementideks tuleb lugeda Bosmina coregoni pelagiaali alamliike (coregonirida), Daphnia cucullata't ja alamliiki Bythotrephes longimanus subsp. balticus (Ischr.). Teised boreaalsed liigid (Latona setifera, Holopedium gibberum, Camptocercus lilljeborgi, Chydorus piger, Podon intermedius, Podon leuckarti) levivad palju laiemalt. Näiteks esineb Holopedium gibberum (Thienemanni (1950) järgi boreo-alpiinne liik laiemas mōttes) arktilisest vööndist kuni Alpideni.

Jälgides nende faunaelementide geograafilist levikut Eesti NSV magevetes selgub, et boreotroopilised liigid esinevad enamasti kogu Eesti territooriumil ning väga eriilmelistes veekogudes. Siia kuuluvad suure ökoloogilise valentsiga liigid, nagu Sida crystallina, Diaphanosoma brachyurum it. Boreaalsed liigid on aga enamasti piiratuma ökoloogilise valentsiga, esinedes kindlailmelistes veekogudes.

${ }^{1}$ Boreaalsed mageveeliigid on eraldatud Behningi (1941) eeskujul, kes arvab siia parasvöötmeliike, kelle levila ei ulatu Alpide ja Kaukaasia mägede joonest lôuna poole. Mereliikidest on siia arvatud Ekmani (1953) Põhja-Atlandi boreaalfauna liigid.

${ }_{2}$ Boreaalsetele liikidele tuleb lisada ka boreotroopilise alamliigi Daphnia longispina subsp. hyalina varieteedid var. pellucida ja galeata.

3 Boreotroopiliste liikide all mōeldakse kõiki ülejäänud liike. 
Nii levib Scapholeberis microcephala peamiselt rabades. Väga ulatuslikult levib Eesti NSV rabades ka arktiline element Bosmina coregoni subsp. obtusirostris f. arctica näol. Taiga elementidest Limnosida frontosa. Ophryoxus gracilis ja osalt ka Bythotrephes cederstroemi esinevad Kirde- ja Kagu-Eesti oligotroofsete ioontega järvedes, kuna Daphnia cristata levila langeb kokku Kōrg-Eesti alaga. Körg-Eesti ala huumusainetevaestes mesotroofsetes ja eutroofsetes järvedes levivad segametsade vööndi elemendid - Daphnia cucullata. Bosmina coregoni pelagiaali alamliigid ia Bythotrephes longimanus subsp. balticus. Huvitav levik on boreaalsel Chydorus piger'il. kes esineb peamiselt Madal-Eesti alal. Lääne-Eestist on leitud ka põhiliselt lōunapoolse levikuga boreotroopilist liiki Daphnia magna't, kes mujal Eestis puudub. Kui kõrvutada Eesti NSV mageveeliste vesikirbuliste faunat naaberalade omaga, siis selgub, et Kesk-Rootsis. Soomes ia Vene NFSV-i loodepiirkondades on meiega võrreldes laiemalt levinud taiga elemendid, vähem aga segametsade vööndi elemendid. Köige suurem sarnasus on meil Läti NSV vesikirbuliste faunaga (Kuptsch, 1926; Ischreyt. 1942), mis mōnevõrra erineb meie omast veelgi suurema segametsade vööndi elementide arvu poolest. Nii on seal Daphnia cucullata, Bythotrephes longimanus subsp. bulticus ja Bosmina coregoni pelagiaali alamliigid veel laiemal alal levinud ning esinevad mōned meil puuduvad alamliigid $(B$. $c$. subso. reflexa Seligo. B. c. subsp. globosa Lillj.). Muus osas ei saa pidada paari liigilist erinevust kuigi oluliseks, sest puuduvate liikide tōenäoline leidmine ühel või teisel alal on nähtavasti vaid aja küsimus. Erinevuseks mereliikide osas on näiteks see. et Evadne spinifera-puudub Eesti NSV vetes, kuid vōiks mõnel juhul esineda Läti NSV vetes Gotlandi süviku piirkonnas.

Oldiselt tuleb Eesti NSV mageveeliste vesikirbuliste faunat iseloomustada kui segametsade vööndile iseloomulikku, kuhu on lisandunud mõningad arktilised ja taiga elemendid.

\section{Eesti NSV-s esinevate vesikirbuliste liikide süstemaatiline ülevaade}

Alloool on esitatud meil leitud vesikirbuliste liigid. koostatud esmakordselt nende ökoloogiline karakteristika Eesti olutes ning toodud andmeid liikide esinemissageduse ja geograafilise leviku kohta Eesti NSV-s.

1. Sida crystallina (O. F. M ülle r). Väga tavaline järvede litoraalis. Leiduh ka jōgedes, tiikides ia riimveelistes merelahtedes (Matsalu lahes 31. VII 1956). Fiitofiil. Veekogude troofsuse ia humoossuse suhtes eurüplastiline. Esines pH väärtuste $<6->9,2$ juures Oligosaproob.

Levinud mandril Saare- ja Hiiumaal.

Tüüpilise vormi kōrval leitud haruldasena ka var, elongata G. O. Sars (Kautla järvest 30 . VII 1943).

*2. Limnosida frontosa G. O. S a r s. Väga haruldane epilimniline liik. Esineb nōrgalt leelisese reaktsiooniga $(\mathrm{pH} \quad 7,28-7,9)$ ja suhteliselt madala $\mathrm{Ca}^{\cdots}$-sisaldusega (alla $30 \mathrm{mg} / 1)$ vetes. Usna eurühumoosne.

Eesti NSV-s leitud vaid Peipsi iärve ja Narva iõe vesikonnas (Peiosi iärvest 10 VI 1909, 10. VII 1909. 26. IX 1956: Lämmijärvest 14. VI 1909; Narva jōest 21. VI 1922: Vaiksest järvest 12. VII 1922: Kalli iärvest 16. VIII 1952; Leegu järvest 16. VIII 1952. Jñuküla järvest $(349)^{1}$ 16. VIII 1957) ning kahest Haania järvest (Kavati järvest 26. VI 1952; Vaskna järvest 26. VI 1952) (mittetäielik levikukaart - Mäemets, 19572).

3. Diaphanosoma brachyurum (L i e v e n). Väga tavaline iärvede litoraalis ia edilimnionis. Esineb ka jōgedes, rabalaugastes, turbaaukudes jne. Leitud Linnulahest (9. VIII 1954) $\mathrm{ka}$ veel $\mathrm{Cl}^{-}$-sisalduse $100 \mathrm{mg} / 1$ puhul. Veekogude troofsuse ja humoossuse suhtes eurüplastiline, esineb $\mathrm{pH}$ väärtuste $4->9.2$ puhul. Oligosaproob. Soojalembene.

Esineb mandril. Saare- ja Hiiumaal (kokku üle 150 leiukoha).

Lisaks tüüpilisele vormile esinevad meil ka var. leuchtenbergianum S. Fischer, var. trontosa Lilljeborg ja var. megalops Lilljeborg.

4. Latona setifera (O. F. M üller). Väheleitud liik. Esineb iärvede litoraalis ja madalamates veekogudes, ka pelagiaalis. Eelistab toitainetevaesemaid ja huumusaineterikkaid veekogusid. Leiti $\mathrm{pH}$ väärtuste $<6-8,42$ juures.

Esineb mandril, Saare- ja Hiiumaal (kokku 25 leiukohta).

5. Holopedium gibberum $\mathrm{Z}$ a d d a ch. Usna sage iärvede epilimnionis ja suuremates rabalaugastes. On leitud ka Narva jōest (17. VII 1922). Esinemine on seotud peamiselt veekogu pH-ga (esines $\mathrm{pH}$ väärtuste 4-7,4 juures), mida väidab ka Weiser (1942). Paljudest neutraalse reaktsiooniga järvedest kaob juba suve keskel nende $\mathrm{pH}$ tõustes üle 7,4. Huvitav oli Holopedium'i vertikaalne levik Urbukse järves (9. VIII 1957). Vee tugeva õitsemise tōttu oli $2-0 \mathrm{~m}$ sügavuse veekihi $\mathrm{pH} 8,4,3 \mathrm{~m}$ sügavusel 6,8 ning

1 Järve number Riikoja (1934) järgi.

2 М я м е т с А. Х., О качественном составе фауны ракообразных летнего зоопланктона озер Эстонской CCP. Käsikiri ENSV TA Zooloogia ja Botaanika Instituudis. 1957. 
põhjas $7 \mathrm{~m}$ sügavusel alla 6 . Holopedium hoidus siin $3-7 \mathrm{~m}$ sügavusse. $\mathrm{CaO}$ suhtes on liik eurüplastilisem, taludes Greze (1933) järgi vee $\mathrm{CaO}$-sisaldust kuni $50 \mathrm{mg} / \mathrm{l}$ (meil esines Murati järves, $\mathrm{CaO}$-sisaldusega $36,5 \mathrm{mg} / \mathrm{l}$, üksikuid eksemplare 24. VI 1952). Eurühumoosne. Eurütermne. Oligosaproob.

Seni teada 47 leiukohta mandril ja ükss Hiiumaal (Väike-Tihu järves 4. VIII 1956) (täiendatud ökoloogiline spekter ja mittetäielik levikukaart Eestis - Mäemets, 1957).

*6. Daphnia magna Stra us. Väga haruldane tiikides ja ajutistes lompides esinev liik. $\beta$-mesosaproob.

Seni leitud Koongas (Lihula raj.) kevadisest lombist (19. V 1957) ja üksikuid ô $\hat{\sigma}$ koos liigiga $D$. pulex Saaremaalt Pidula kalakasvatuse Daphnia-tiigist (24. VII 1956). Senine pôhjapoolseim leid Baltikumis pärineb Liepaja (Liibavi) ümbrusest (Ischreyt, 1942). Koongasse on liik sattunud nähtavasti lindude vahendusel. Pidulasse vōib $D$. magna olla toodud inimese poolt (on kasvatatud reas Eesti NSV kalakasvatustes). ${ }^{1}$

7. Daphnia pulex D e G e e r. Väga tavaline tiikides ja ajutistes väikeveekogudes. Mõned leiud ka järvede litoraalist, jôgedest $\mathrm{ja}$ isegi Soome lahest (Riikoja, 1929). B-mesosaproob.

Esineb kogu mandril, Saare- ja Hiiumaal.

Meil konstateeritud ka teisendit var. obtusa Kurz.

8. Daphnia longispina O. F. M ü 11 e r. Väga varieeruv, süstemaatiliselt raskesti jaotatav liik. Näib, et Lilljeborgi (1900), Behningi (1941) jt. autorite kahte liiki $-D$. longispina O. F. Müller ia D. hyalina (Leydig) - tuleb käsitleda ühe liigi kahe alamliigina, nagu teeb Rõlov (1935).

Daphnia longispina subsp. longispina (O. F. Müller).

Tavaline järvede litoraalis, lompides jt. väikeveekogudes. Esineb samuti jōgede ripaalis (Kasari jōes 27. VII 1956), mōnes sügavas järves (näit. Valgjärv (1180)), ka epilimnionis ja metalimnionis (var. tenuitesta G. O. Sars lähedane vorm). Alamliiki leiti $\mathrm{pH}$ väärtuste 6,4-8.6 juures (Manuilova (1949) järgi on $\mathrm{pH}$ alampiiriks 5,3). Veekogu troofsuse ja humoossuse suhtes eurüplastiline. $\beta$-mesosaproob. Esineb mandril, Saare- ja Hiiumaal ning Rammu saarel.

Daphnia longispina subsp. hyalina (Leydig).

Usna sage järvede pelagiaalis. Leitud ka Narva veehoidlast (26. IX 1956 - var. galeata G. O. Sars) ia isegi Soome lahest soolsuse juures kuni 38\% (Riikoja, 1928). Esines vetes, mille $\mathrm{pH}>7$ (Manuilova järgi on $\mathrm{pH}$ alampiiriks 6,8).

Veekogu humoossusesse suhtuvad eri varieteedid erinevalt. Meil täiesti tavalised var. galeata ia var. lacustris G. O. Sars on kõige eurühumoossemad, kuna haruldased var. hyalina Leydig ja var. pellucida P. E. Müller (viimast on leitud vaid Vagula järvest 29. VI 1952) esinevad eranditult oligohumoossetes järvedes.

Alamliik on levinud peamiselt mandril ning ainult var. galeata esineb veel Saaremaal Järise järves (12. VIII 1954, 26. VII 1956).

9. Daphnia cucullata (G. O. S a rs). Väga tavaline Eesti eutroofsete ja mesotroofsete järvede epilimnionis. Leitud ka jōgedest (Emajōgi - Lumberg, 1956; Narva jõgi) ja Soome lahest (Riikoja, 1928, 1929, 1931; Schönberg, 1950), kus esines soolsuse juures kuni $7 \%$. Leitud peamiselt oligohumoossetes kuni mesohumoossetes vetes $\mathrm{pH}$ väärtuste $6.8-88$ juures.

Seni umbes 100 leiukohta, neist enamik Kōrg-Eesti alal. Saartelt pole leitud. Soome lahes tavaliselt Tallinn-Helsingi joonest ida pool (mittetäielik levikukaart - Mäemets, 1957). Meil leitud f. apicata Kurz, f. berolinensis Schoedler, f. cucullata G. O. Sars, f. kahlbergensis Schoedler, f. procurva (Pihkva järvest - Samsonov, 1912) ja f. incerta Richard.

10. Daphnia cristata G. O. S a rs. Usna sage iärvede epilimnionis. Leitud ka Narva jõest (31. VII 1922). Esineb peamiselt oligotroofsetes ja mesotroofsetes. kuid ka eutroofsetes vetes. Leitud enamasti oligohumoossetest ia mesohumoossetest järvedest $\mathrm{pH}$ väärtuste 6,0-8.6 iuures. (Manuilova järgi on pH alampiiriks 5,6). Eurütermne.

Meil üle 70 leiukoha, neist enamik Körg-Eesti alal. Saartel ei ole leitud (mittetäielik levikukaart - Mäemets, 1957).

11. Simocephalus vetulus (O, F. M ü 11 e r). Väga tavaline järvede litoraalis, jōgedes ia väikeveekogudes. Esines ka riimveelises Väikses Väinas (19. VII 1956). Leitud pHväärtuste $6,6-9,2$ juures.

Levinud kogu mandril ja saartel.

12. Simocephalus exspinosus ( $\mathrm{Koch}$ ). Seni suhteliselt vähe leitud. Esineb peamiselt väikestes seisuveekogudes (lombid, tiigid), kuid ka vooluvetes $\mathrm{ja}$ väheste järvede litoraalis.

Leiud Eesti NSV mandrilt (paarkümmend leiukohta). Lisaks tüüpilisele vormile esineb ka var. congener Schoedler.

1 Linko (1901) märgib Daphnia magna leiukohana soolaseid laguune linna, nimega «Hapsal», juures. Tõenäoliselt on tegemist Haapsalu linnaga. 
13. Simocephalus serrulatus ( $\mathrm{Koch}$ ). Võrdlemisi haruldane liik. Leitud düstroofsete järvede ${ }^{1}$ litoraalist, pruuniveelistest ajutistest lompidest ja kloriididerikkast rannajärvest - Põldmaa lahest (787) - 22. VII 1956. Esines $\mathrm{pH}$ väärtuste $5,5-8,1$ juures.

Leitud mandrilt ja Saaremaalt (kokku 13 leiukohta).

14. Scapholeberis mucronata (O. F. M ü $11 \mathrm{e}$ r). Väga tavaline järvede litoraalis, vooluvetes, väikeveekogudes ning klorididerikastes rannajärvedes. Troofsuse ja humoossuse suhtes eurüplastiline. Esines $\mathrm{pH}$ väärtuste $\langle 6-\rangle 9,2$ juures. Fütofiil. Oligosaproob.

Levinud kogu mandril ja saartel. Meil esineb f. cornuta Schoedler ja f. fronte laevi (P. E. Müller).

15. Scapholeberis aurita (S. F i s che r). Väga haruldane liik. Seni teada 2 leiukohta: Selja oja 18. VII 1929 (Lepiksaar) ja tarna täiskasvanud lomp Ãnküla juures Jōgeva rajoonis (3. VII 1957).

*16. Scapholeberis microcephala (L i 11 j e borg MS) G. O. S a rs. Väga haruldane vesikirbuline. Seni leitud rabalaukast Veisjärve juures (14. VII 1955) ning Sphagnum'it täiskasvanud laukaist Loosalu (23. VII 1955), Tänavjärve (6. VIII 1956) ja Tähtvere (16. X 1957) rabades.

17. Ceriodaphnia reticulata ( $\mathrm{J}$ u rin e). Usna tavaline järvede litoraalis, jõgede ripaalis $\mathrm{ja}$ väikeveekogudes. Leitud ka riimveelistest merelahtedest (Käina lahest 5 . VIII 1956; Rame lahest 18. VII 1956). Talub Behningi järgi soolsust kuni $3,5 \%$. Esines pH väärtuste $6,6-9,14$ juures.

Meil levinud kogu mandril, Saare- ja Hiiumaal ning Vormsil (Prest-Wiek 30. VII 1956). Kokku üle 50 leiukoha. Kevadistes ja sügisestes lompides esineb peamiselt var. serrata G. O. Sars.

18. Ceriodaphnia megalops G. O. S a rs (C. megops G. O. S a r s). Haruldane liik. Leitud järvede litoraalist, väikeveekogudest ja vooluvetest.

Esineb mandril, Saare- ja Hiiumaal. Leiukohad: Soova jōgi (7. IX 1929 - Lepiksaar), Pehme järv (9. VII 1952), Leisi jõgi (23. VII 1956), keskmine Tihu järv (4. VIII 1956), Lindjärv (19. IX 1956), Suur-Seapilli järv (19. IX 1956), Tudre järv (19. IX 1956), Anküla lomp (Jōgeva raj. - 3. VII 1957), Vōlla raba oja (30. VII 1957), Jōnni järv (29. VIII 1957).

19. Ceriodaphnia pulchella G. O. S a rs. Väga tavaline järvede litoraalis ja pelagiaalis, jōgedes ja väikeveekogudes. Leitud ka kloriididerikastest rannajärvedest (Mullutu lahest 10. VIII 1954). Esines $\mathrm{pH}$ väärtuste $7,0->9,2$ juures (Manuilova järgi on $\mathrm{pH}$ alampiiriks 6,9). Humoossuse suhtes eurüplastiline.

Levinud kogu mandril ja saartel.

Lisaks tüüpilisele vormile esineb meil ka var. pseudohamata Bowkievicz (näit. Kudani järves 1. VIII 1956).

20. Ceriodaphnia quadrangula (O. F. M ülle r). Tavaline järvede litoraalis ja pelagiaalis, samuti väikeveekogudes ja vooluvetes. Esineb ka Soome lahes (Riikoja, $1925,1928,1929$, 1931; Schönberg, 1950) soolsuse juures kuni 7,7\%o, hoidudes ülemistesse horisontidesse (meres peamiselt teisend var. hamata G. O. Sars). Magevees asustab väga eriilmelisi veekogusid, olles väga arvukas just düstroofsetes vetes (näit. Loosalu järves, kus $\mathrm{pH}$ on 4$)$.

Levinud (ka var. hamata) mandril ja Saaremaal.

21. Ceriodaphnia affinis $\mathrm{L} \mathrm{i} 11 \mathrm{j}$ e bo r g. Meil väga vähe leitud. Senised leiud Harku järve pelagiaalist (7. X 1929 - Lepiksaar) ja Saaremaalt Maade ojast (22. VII 1956).

22. Ceriodaphnia setosa $M$ atile. Meil väga haruldane. Ainus leid Tartu lähedalt turbaaugust (Lepiksaar).

23. Ceriodaphnia laticaudata P. E. M ülle r. Väga haruldane liik. Seni leitud vaid mōnede järvede litoraalist ja turbaaukudest.

Leiukohad: Pangodi järv (Samsonov, 1908); turbaauk Tartu juures (Lepiksaar); keskmine Tihu järv (4. VIII 1956); turbaauk Prassi järve juures (5. VIII 1956); lomp Pabra järve juures (13. VII 1957).

24. Ceriodaphnia rotunda G. O. S a r s. Haruldane. Esineb peamiselt väikeveekogudes.

Leiukohad: turbaaugud Tartu ja Konguta juures (Lepiksaar); Kaarmise järv (24. VII 1956); Vodja tiigid (18. IX 1956); Anküla lomp (3. VII 1957); lomp Kalijärve (1281) juures (22. X 1957).

25. Moina rectirostris Leydig. Haruldane. Esineb väikeveekogudes. Soojalembene. $\beta$-mesosaproob.

1 Düstroofsete järvede all mōeldakse oligotroofseid polühumoosseid järvi. 
Leiukohad: temporaalsed lombid Rakvere liivaaugus (23. VII 1929 - Lepiksaar): Vingri linaligu (5.-7. VIII 1933) ja Lüüdi lomp (11. VIII 1933) end. Lõuna-Valgamaal (Mikelsaar); Täätsi lomp Saaremaal Orissaare rajoonis (20. VII 1956).

26. Bosmina longirostris (O. F. M ülle r). Väga tavaline järvede litoraalis ja pelagiaalis, jõgedes ia väikeveekogudes. Leitud ka kloriididerikastest rannaiärvedest (Mullutu lahest 10. VIII 1954). Esines $\mathrm{pH}$ väärtuste $\langle 6-\rangle 9,2$ juures (Manuilova järgi on $\mathrm{pH}$ alampiiriks 5,6). Eurütermne. Levinud kogu Eesti NSV territooriumil.

Meil leitud var, typica (O. F. M üll e r), var. cornuta Jurine, var. brevicornis Hellich, var. curvirostris Fischer, var. similis Lilljeborg ja var. pellucida Stingelin.

27. Bosmina coregoni $\mathrm{B}$ a i $\mathrm{r}$ d. Tugevalt varieeruv, süstemaatiliselt mitmeks raskesti eraldatavaks alamliigiks jagunev liik, mille Rühe jagas kaheks alamliikide reaks (Rõlov, 1935): longispina-rida ja coregoni-rida.

Longispina-rea alamliikidest on haruldasem subsp. longispina Leydig, kes asustab peamiselt suurte järvede (Peipsi järv, Võrtsjärv, Narva veehoidla) pelagiaali, kus vesi on neutraalse või leelisese aktiivse reaktsiooniga.

Eelmisele liigile väga lähedane (esinevad pidevad üleminekud) subsp. obtusirostris G. O. Sars esineb väga sageli järvede pelagiaalis ja litoraalis, samuti väikeveekogudes. Subsp. obtusirostris on vōrdlemisi eurühumoosne, eelistades polühumoosseid veekogusid (eriti rabalaugastes esinev f. arctica Lilljeborg). Alamliiki on leitud $\mathrm{pH}$ väärtuste $4-9,2$ juures.

On levinud kogu Eesti NSV territooriumil. Teisendit var. maritima P. E. Müller esineb ka meres (Läänemeres. Riia lahes, Soome lahes).

Magevete subsp. obtusirostris'e teisendeist ja vormidest ${ }^{1}$ (lisaks vormidele f. obtusirostris G. O. Sars, f. arctica Lilljeborg) on meil määratud veel var. procumbens G. O. Sars (Imsi järves 23. VII 1929 - Lediksaar) ja f. cisterciensis Rühe (Riikoia, 1944). Longispina-rea alamliikidele lisab Riikoja (1944) küsimärgi all veel alamliigi subsp. stingelini Burckhardt (Aegviidu Kalijärvest 17. VII 1935).

Coregoni-rea alamliigid esinevad järvede pelagiaalis (nn. pelagiaali-Bosmina). Tavalised oligohumoossetes kuni mesohumoossetes järvedes. Köige kõrgemat humoossust talub nähtavasti subss. lilljeborgi G. O. Sars. kes esineb polühumoossetes iärvedes Kirikumäe järves ja Pikkjärves (717). Pelagiaali-Bosmina alamliigid esinesid $\mathrm{pH}$ väärtuste $6-8,8$ juures.

See Rōlovi (1940) järgi palearktilise regiooni segametsade vöötme lääneosale iseloomulik rühm (nimetatud ka Balti-Bosmina'ks) on meil levinud mandril (enamasti KoñrgEesti alal) ja vaid ühel juhul on leitud teda Saaremaalt (Pikkjärvest (717) 21. VII 1956). Seni on teada meie vabariigist ligi 100 pelagiaali-Bosmina leiukohta (mittetäielik levikukaart - Mäemets, 1957).

Eesti NSV-s on konstateeritud järgmisi alamliike: subsp. longicornis Schoedler, subsp. kessleri Uljanin, subsp. lillieborgi G. O. Sars, subsp. coregoni Baird, subsp. gibbera Schoedler, subsp. thersites Poppe ja subsp. crassicornis Lilljeborg (leitud vaid Vagula järvest 29. VI 1952, Tamula järvest 28. VI 1952 ja Korijärvest 20. VII 1952).

28. Iliocryptus sordidus (L i evi n). Harváesinev liik. ${ }^{2}$ Leitud järvede profundaalis. Iliofiil.

Senised leiukohad: Kahala järv (29. VII 1929), turbaauk Tartu juures (mōlemad Lepiksaare leiud) ja Veski lais (3. VIII 1956).

29. Iliocryptus agilis Kurz. Nähtavasti meil kõige sagedam Iliocryptus. Elupaik järvede profundaalis, vististi ka litoraalis.

Senised leiud: Neeruti Kaksjärvest 25. VIII 1929 (Lepiksaar), Kise järvest 19. VI 1952, Parika järvest 18. VI 1953, Lavassaare järvest 20 . VI 1953, Järlepa järvest 1. VII 1953, Järise järvest 26. VII 1956 Ohtja järvest (?) 26 . VII 1956, Tamma järvest 31 . VII 1956, Järveotsa järvest 8. VIII 1956. fiil.

30. Iliocryptus acutifrons G. O. S a r s. Väga haruldane järvede profundaali liik. Ilio-

Seni 3 leidu: Olemiste järvest 31. VII 1904 (Levander, 1908), Veisjärvest 24. X 1956 ja Männikjärvest 10. XI 1955.

31. Lathonura rectirostris (O. F. M ü 11 e r). Usna sage väikeveekogudes ja järvede litoraalis. Esines $\mathrm{pH}$ väärtuste $5,7-8,6$ juures (Behningi (1941) ja Poulseni (1928) järgi on $\mathrm{pH}$ piirideks $7-8$ ).

Leitud kogu mandrilt, Saare- ja Hiiumaalt (kokku 23 leiukohta).

32. Macrothrix laticornis ( $\mathrm{J}$ u ri n e). Haruldane. Leitud järvede litoraalist ja väikeveekogudest. OKs leid ka Pärnu jōest.

1 Autoril on obtusirostris-rühma materjal pōhjalikumalt alles analüüsimata.

2 Iliocryptus'te leiukohtade vähesus sôltub nähtavasti proovide kogumise metoodikast: planktobentilise eluviisi tôttu satuvad nad planktoniproovidesse vaịd harva (peamiselt Iliocryptus'te postabdomen'id). 
Leiukohad: 4 veekogu Saaremaal - Karujärv (18. VI 1929 - Lepiksaar), Täätsi lomp (20. VII 1956), Kaarmise järv (24. VII 1956), Süvaja laht (27. VII 1956) - ja 2 veekogu Eesti NSV mandril - Pärnu jōgi (27. V 1937), Rohu mõisa tiik VäikeMaarja rajoonis (23. IX 1956).

*33. Macrothrix rosea (J u rin e). Väga haruldane. Leiukohad: 2 veekogu Saaremaal - Täätsi lomp (20. VII 1956), Tähtsoo järv (24. VII 1956) - ja 2 veekogu mandril - Paatre järv (20. VIII 1943), Pabra järv (20. VI 1952).

34. Macrothrix hirsuticornis $\mathrm{N}$ ordma n et B r a y. Lumberg (1956) mainib liiki Emajōes.

35. Ophryoxus gracilis G. O. S a r s. Võrdlemisi haruldane. Asustab järvede litoraali ja pelagiaali. Esineb peamiselt pehmeveelistes mesohumoossetes kuni polühumoossetes järvedes, kōrgeima Ca -hulgaga $25,9 \mathrm{mg} / \mathrm{l}$. Vastupidiselt Wesenberg-Lundi väitele (1939) on teda leitud ka leelisese reaktsiooniga vetes ( $\mathrm{pH} 6-8,98)$.

Senised leiukohad enamasti Kagu-Eestis: Pulli järv (18. VI 1952), Saarjärv (18. VI 1952), Pabra järv (20. VI 1952). Kirikumäe järv (21. VI 1952), Preeksa järv (21. VI 1952), Ubajärv (10. VII 1952), Koobassaare järv (12. VII 1952, 10. VII 1956, 23. VII 1957), Sōdaaluse järv (15. VII 1957), Pedeja järv (16. VII 1957), Meelva järv (14. X 1957), Palu järv (1099) (22. X 1957). Pōhja-Eestis esineb Viitna Pikkjärves (6. VII 1929 - Lepiksaar) ja Räätsma järves (26. VII 1954) (mittetäielik levikukaart - Mäemets, 1957).

36. Streblocerus serricaudatus (S. Fis ch e r). Võrdlemisi haruldane. Esineb peamiselt raba-, vahel $\mathrm{ka}$ soojärvede litoraalis ja väikeveekogudes. Leitud $\mathrm{pH}$ väärtuste $<6-8,18$ juures.

Mandrilt ja Saaremaalt kokku 15 leiukohta.

37. Drepanothrix dentata (E uren). Vördlemisi haruldane. Leitud peamiselt mesohumoossete kuni polühumoossete järvede litoraalist. Esineb pH väärtuste 5,5-8,2 juures.

Seni teada 16 leiukohta mandrilt ja Saaremaalt.

38. Acantholeberis curvirostris (O. F. M ü $11 \mathrm{e} \mathrm{r}$ ). Rabalaugastes ja -järvedes vōrdlemisi sage liik. Esineb peamiselt happelise reaktsiooniga vees.

Seni teada mõnikümmend leidu mandrilt ja Saaremaalt.

39. Eurycercus lamellatus (O. F. M ü 11 e r). Väga tavaline järvede litoraalis, jōgedes ja ka väikeveekogudes. Fütofiil. Troofsuse ja humoossuse suhtes eurüplastiline. Leitud $\mathrm{pH}$ väärtuste $6->9,2$ juures.

Meil levinud kogu mandril, Saare- ja Hiiumaal.

40. Camptocercus rectirostris $\mathrm{Schoedler.} \mathrm{Võrdlemisi} \mathrm{sage} \mathrm{järvede} \mathrm{litorảalis.}$ Leitud ka jōgedest ning väikeveekogudest. Fütofiil. Esineb $\mathrm{pH}$ väärtuste $5,7-8,6$ juures.

Peamiselt Pōhja-Eestis levinud liik. Uks leid pärineb ka Saaremaalt (Kaarmise järvest 24. VII 1956). Oldse umbes 30 leiukohta.

Meil konstateeritud ka var. biserratus Schoedler (Suur-Toatse järves 7. VIII 1956).

41. Camptocercus lilljeborgi Schoedler. Esineb sama tihti ja samasugustes tingimustes kui $C$. rectirostris. Leitud $\mathrm{pH}$ väärtuste $7,2-8,18$ juures.

Teada paarkümmend leiukohta, peamiselt Eesti NSV mandri pōhjaosast.

42. Acroperus harpae B a i r d. Väga tavaline järvede litoraalis, jōgede ripaalis ja väikeveekogudes, esineb ka kloriididerikastes rannajärvedes. Talub soolsust kuni $5 \%$ (Behning). Fütofiil. Troofsuse ja humoossuse suhtes eurüplastiline. Leitud pH väärtuste $4-9,14$ juures. Oligosaproob.

Levinud kogu mandril, Saare- ja Hiiumaal.

43. Alonopsis elongata G. O. S a r s. Tavaline liik peamiselt toitainetevaeste järvede litoraalis, rea jōgede ripaalis ja rabalaugastes. Eurühumoosne. Leitud pH väärtuste $4-8,9$ juures.

Esineb kogu mandril ja Saaremaal (kokku üle 70 leiukoha).

*44. Kurzia latissima (K u r z). Väga haruldane liik. Kiruvere järvest (18. IX 1956) leitud 2 of $\hat{o}$ isendit.

45. Alona quadrangularis (O. F. M ü $11 \mathrm{e}$ ): Tavaline järvede ja jõgede kaldavöös ning väikeveekogudes.

Levinud mandril ja Saaremaal.

46. Alona affinis Le y dig. Väga tavaline järvede ja jōgede kaldavöös ning väikeveekogudes. Esineb ka kloriididerikastes rannajärvedes. Väga eurüplastiline troofsuse ja humoossuse suhtes. Leitud $\mathrm{pH}$ väärtuste $4-9,2$ juures. Levinud kogu mandril ja saartel.

47. Alona costata G. O. S a r s. Tavaline järvede litoraalis, ka väikeveekogudes. Fütofiil. Esineb $\mathrm{pH}$ väärtuste $7,0->9,2$ juures. Seni üle 60 leiukoha mandrilt ja Saaremaalt. 
48. Alona guttata G. O. S a r s. Tavaline järvede litoraalis. Leitud ka väikeveekogudest ja kraavidest. Fütofiil. Leitud $\mathrm{pH}$ väärtuste $\langle 6-\rangle 9,2$ juures.

Meil üle 50 leiukoha mandril, Saare- ja Hiiumaal ning Rammu saarel. Meil üsna sage ka var, tuberculata Kurz.

49. Alona tenuicaudis G. O. S a rs. Esineb üsna sagedasti järvede litoraalis, kuid enamasti väikesearvulisena. Leitud ka Emajōest (Sepp), väikeveekogudest ning riimveelistest merelahtedest (Matsalu lahest 31. VII 1956, Käina lahest 5. VIII 1956). Esines $\mathrm{pH}$ väärtuste $6,9-8,6$ juures. Nähtavasti üsna eurühumoosne (esines polühumoosses Leegu järves 16. VIII 1952, Võlla raba ojas 30. VII 1957).

Seni teada 28 leiukohta mandril, Saare- ja Hiiumaal.

50. Alona rectangula G. O. S a rs. Väga tavaline järvede, jõgede ja väikeveekogude taimestikuvöös. Esineb sageli ka riimveelistes lahtedes (näit. Väikses väinas 19. VII 1956). Talub soolsust $13-14 \%$ (Behning). Leitud peamiselt leelisese reaktsiooniga vees $(\mathrm{pH}>7)$.

Meil levinud mandril, saartel ja rannikuvetes.

51. Alona intermedia G. O. S a r s. Väga haruldane liik. Meil leitud seni Olemiste järvest (31. VII 1904 - Levander, 1908) ja Koobassaare järvest (12. VII 1952).

52. Rhynchotalona rostrata ( $\mathrm{Ko} \mathrm{ch})$. Võrdlemisi vähe leiukohti. Esineb peamiselt järvede litoraalis. Konstateeritud ka Emajōes (Lumberg) ja Narva jōes (17. VII 1922, 7. VIII 1922, 18. X 1922, 27. VIII 1938).

Paarkümmend leiukohta mandril ja Saaremaal.

53. Rhynchotalona falcata (G. O. S a rs). Vōrdlemisi haruldane. Esineb järvede litoraalis. Leitud ka Emajōest (Lumberg). Esineb $\mathrm{pH}$ väärtuste $<6-9,2$ juures.

Kokku 27 leiukohta mandrilt, Saare- ja Hiiumaalt.

54. Leydiga leydigi ( $\mathrm{Schoedle} \mathrm{r).} \mathrm{Haruldane}{ }^{1}$ järvede profundaalis esinev plankto-bentiline vesikirbuline. Leitud peamiselt mesotroofsetest ja eutroofsetest oligoning mesohumoossetest järvedest. Esines $\mathrm{pH}$ väärtuste $6,4-8,4$ juures. $^{2}$

Leiukohad: Pangodi järv (20. III 1906 - Samsonov, 1908), Harku järv (7. X $1929-$ Lepiksaar), Vagula järv (Riikoja, 1944), Kuremaa järv (1.-3. VII 1951), Raigastvere järv (14. VII 1951). Viliandi järv (8. VIII 1952), Piigandi järv (10. VI 1953, 19. III 1957), Konsu järv (23. VII 1953), Uiakatsi järv (8. VII 1954), Leisi jōgi Saaremaal (23. VII 1956).

55. Graptoleberis testudinaria ( $\mathrm{F}$ i s c h e r). Tavaline litoraaliliik järvedes. Esineb ka jõgedes ja väikeveekogudes (rabalaukad, turbaaugud). Leitud $\mathrm{pH}$ väärtuste $6->9,2$ juures.

Levib meil kogu mandril, Saare- ja Hiiumaal (kokku üle 60 leiukoha).

56. Alonella excisa ( $\mathrm{F}$ is $\mathrm{ch}$ e r). Tavaline järvede litoraalis ja väikeveekogudes (eriti rabalaugastes). Esineb ka jõgedes. Fütofiil. Leitud $\mathrm{pH}$ väärtuste $5,5-9,2$ juures. Eurühumoosne.

Teada üle 75 leiukoha mandrilt, Saare- ja Hiiumaalt.

57. Alonella exigua ( $\mathrm{L}$ i $11 \mathrm{j}$ e b o $\mathrm{g}$ ). Usna sage järvede litoraalis. Esineb ka väikeveekogudes. Leitud $\mathrm{pH}$ väärtuste $4-9$ juures.

Kokku üle 40 leiukoha mandril, Saare- ja Hiiumaal.

Meil leitud ka f. mutica Lilljeborg (Tamme lais 3. VIII 1956).

58. Alonella nana (B a i $\mathrm{rd}$ ). Tavaline järvede litoraalis, harvem esineb pelagiaalis. Leidub ka rabalaugastes ja teistes väikeveekogudes, samuti jõgedes. Leitud $\mathrm{pH}$ väärtuste $<6-9,2$ juures.

Teada üle 90 leiukoha mandril, Saare- ja Hiiumaal.

59. Peracantha truncata (O. F. M ülle r). Väga tavaline järvede litoraalis, väikeveekogudes ning jōgedes. Esineb ka riimveelistes merelahtedes. Fütofiil. Leitud $\mathrm{pH}$ väärtuste $<6-9$ juures.

Levinud kogu mandril, Saare- ja Hiiumaal.

60. Pleuroxus laevis G. O. S a rs. Usna haruldane liik. Leitud järvede litoraalis. Esineb peamiselt leelisese aktiivse reaktsiooniga järvevees.

Teada umbes tosin leiukohta mandri, Saare- ja Hiiumaa järvedest.

61. Pleuroxus trigonellus (O, F. M ülle r). Kõige tavalisem Pleuroxus'e liik. Esineb peamiselt järvede litoraalis, kuid ka väikeveekogudes ning vooluvetes. Konstateeritud (Lepiksaar) ka riimveelises merelahes (Haapsalu laht 26. VI 1929). Leitud vetes $\mathrm{pH}$-ga üle 6,9.

Esineb umbes 30 veekogus mandril, Saare- ja Hiiumaal. puhul.

${ }^{1}$ Mitteleidmine võib sõltuda proovide kogumise metoodikast nagu Iliocryptus'tegi

${ }^{2}$ Arvesse on vōetud pōhjalähedase vee $\mathrm{pH}$. 
62. Pleuroxus uncinatus B a i rd. Usna haruldane. Leitud järvede litoraalist. Füto-

fiil. Esineb nähtavasti leelisese reaktsiooniga vetes.

Seni leitud vaid mandrilt (13 leiukohta).

*63. Pleuroxus aduncus ( $\mathrm{u}$ ri n e). Haruldane. Leitud järvede litoraalist ja vooluvetest. Esineb ka riimveelistes merelahtedes.

Leiukohad ainult Saaremaal (Täätsi lomp 20. VII 1956, Maade oja 22. VII 1956 , Pōldmaa laht 22. VII 1956, Leisi jōgi 23. VII 1956, Kaanda järv 26. VII 1956) ja Matsalu lahes (31. VII 1956).

64. Chydorus globosus B a i r d. Vōrdlemisi haruldane. Leitud enamasti järvede litoraalist, harva vooluvetest ja väikeveekogudest. Esines $\mathrm{pH}$ väärtuste $7,2-8,9$ juures.

Seni teada 20 leiukohta mandril ja Saaremaal.

65. Chydorus ovalis Kurz. Vōrdlemisi haruldane. Esineb väga mitmesugustes veekogudes.

Leitud Prosså järvest (11. VIII 1928), turbaaugust Tartu juures (mõlemad leiud Lepiksaarelt), Narva jōest (21. VI 1922), Rōuge Kōrbjärvest (4. VII 1955), rabalaukast Veisjärve juures (14. VII 1955), lombist Suur-Kirjaku järve juures (15. VIII 1957), Meelva järvest (14. X ja 22. X 1957), Tähtvere rabast (16. X 1957), kraavist Meelva järve ääres (22. X 1957), Elistvere lombist (26. X 1957).

*66. Chydorus latus G. O. S a r s. Väga haruldane liik. Samsonov (1908) märgib selle liigi leidu Pangodi järvest küsimärgi all. Esinenud Pabra (20. VI 1952) ja Kiruvere (18. IX 1956) järves.

67. Chydorus sphaericus O. F. M üller. Väga tavaline. Esineb igasugustes veekogudes ja biotoopides. Leidub ka Riia lahes. Väga arvukas just eutroofsetes järvedes. Puudus polühumoosses väga happelise veereaktsiooniga ( $\mathrm{pH} \mathrm{4}$ ) Loosalu järves. Eurütermne. $\mathbf{\beta}$-mesosaproob.

Levinud kogu mandril ja saartel.

Meil leitud reast veekogudest ka var. caelatus Schoedler.

68. Chydorus gibbus Li $11 \mathrm{jeb}$ org. Väga haruldane. Leitud järvede pelagiaalist ja litoraalist.

Senised leiud: Uljaste järvest 3. VII 1929 (Lepiksaar), Lämmijärvest 22. VII 1909, Juusa järvest 9 . VII 1954.

*69. Chydorus piger G. O. S a r s. Võrdlemisi haruldane. Leitud järvede litoraalist ja ka pelagiaalist. Esines $\mathrm{pH}$ väärtuste $7-9,2$ juures.

Enamik leide Saaremaalt ja Loode-Eestist.

Seni teada 13 leiukohta: Saadjärv (23.-25. VII 1951), Piigandi järv (10. VI 1953), Järveküla järv (selle osas Pōlde järves, 20. VII 1956), Kiljatu järv (25. VII 1956), Pōdragu järv (25. VII 1956), Saka järv (25. VII 1956), Sarapiku järv (25. VII 1956), Järise järv (26. VII 1956), Kooru jărv (26. VII 1956), Pikanina järv (7. VIII 1956), Valge järv ((290) 8. VIII 1956), Järveotsa järv (8. VIII 1956), Ulemiste järv (20. IX 1956).

70. Monospilus dispar G. O. S a r s. Vōrdlemisi haruldane. Esineb peamiselt järvede liivase põhjaga litoraalis, kuid ka madalate järvede pelagiaalis. Peale järvede on leitud veel jōgedest (Keila jōest 19. VII 1929 - Lepiksaar, Narva jōest 7. IX 1922, 18. X 1922), väikeveekogudest (Süvaja lahest Saaremaal 27. VII 1956) ning kloriididerikastest rannajärvedest (näit. Mullutu lahest 10 . VIII 1954). Leitud $\mathrm{pH}$ väärtuste $6,6-8,6$ juures.

Seni teada 18 leidu mandrilt (peamiselt Loode-Eestist) ja Saaremaalt.

*71. Anchistropus emerginatus G. O. S a r s. Väga haruldane. Leiud järvede litoraalist. Tuntud mageveehüdra parasiidina (Borg, 1935).

Seni leitud üksikute eksemplaridena Eesti NSV mandril neljast järvest: Punamäe järvest (2. VIII 1943), Suur-Kirjaku järvest (24. VII 1954), Mägialuse järvest (15. VII 1957), Ubajärvest (22. VII 1957).

72. Polyphemus pediculus (L.). Väga tavaline. Esineb järvede ja jõgede kaldavöös ning väikeveekogudes, hoidudes tihedatesse parvedesse. Leidub ka kloriididerikastes rannajärvedes. Arvukam näib olevat huumusaineterikastes vetes. Leitud pH väärtuste $4->9,2$ juures.

Levinud kōikjal mandril ja saartel.

73. Podon polyphemoides ( $\mathrm{L}$ e u $\mathrm{ck}$ a $\mathrm{rt}$ ). Väga tavaline meres. Neriitiline, ülemisi veekihte asustav liik. Köige eurühaliinsem vesikirbuline: soolsuse piirid $1,05-35,1 \%$, optimaalne soolsus $3,55-31,1 \%$ (Rammner, 1930). Temperatuuri piirid Rammneri andmeil $2,46-17,92^{\circ} \mathrm{C}$, optimaalne $t^{\circ} 10-15^{\circ} \mathrm{C}$.

Levinud kõikjal Läänemeres, Soome ja Riia lahes. Esines ka merest tugevasti isoleerunud Mullutu. lahes (10. VIII 1954). 
74. Podon intermedius $\mathrm{L} \mathrm{i} 11 \mathrm{j}$ e b org. Eelmisest haruldasem. Neriitiline liik. Esineb peamiselt ülemistes veekihtides, kus soolsuse piirid kõiguvad 2,4-35,35\% (optimaalne soolsus $3,55-35,33 \%$ ) ja temperatuuri piirid $4,8-20,59^{\circ} \mathrm{C}$ (optimaalne temperatuur $\left.9-18^{\circ} \mathrm{C}\right)$ (Rammner).

Esineb Läänemeres, Soome ja Riia lahes.

75. Podon leuckarti G. O. S a r s. Kōige haruldasem Podon meie vetes. Neriitiline liik. Hoidub Soome lahes sügavamatesse veekihtidesse, Vee soolsuse piirid köiguvad $6,15-35,49 \%$ (optimaalne soolsus $23-35^{\circ} \%$ ) ja temperatuuri piirid $0-17,39^{\circ} \mathrm{C}$ (optimaalne temperatuur $10-17^{\circ} \mathrm{C}$ ) (Rammner).

Esineb meil Läänemeres. Leidub ka Soome lahes, kus tema idapoolseim leiukoht on Vaindloo saare lähedal.

76. Evadne nordmanni Love n. Meres väga tavaline. Neriitiline liik. Esineb ülemistes veekihtides, kus soolsuse piirid kōiguvad 1,33-35,4\% (optimaalne soolsus $2-35 \%$ ) ja temperatuuri piirid $1-22,6^{\circ} \mathrm{C}$ (optimaalne temperatuur $6-18^{\circ} \mathrm{C}$ ) (Rammner).

Esineb Läänemeres, Soome ja Riia lahes.

77. Bythotrephes longimanus L ey dig. ${ }^{1}$ Väga haruldane. Suuremate järvede epilimnionis.

Leiukohad: Peipsi järv (10. VI 1909, 10. VII 1909, 26. IX 1956), Saadjärv (1. VIII 1925 - Lepiksaar 2 , 23. - 25. VII 1951), Aheru järv (16. VII 1952). Esineb tōenäoliseit ka Võrtsjärves (Bythotrephes sp. - Levander, 1920).

78. Bythotrephes cederstroemi Schoedle r. Väga haruldane. Leitud madalate huumusaineterikaste järvede pelagiaalist (ka litoraalist). Eurütermne, talub temperatuuri kuni $28-30^{\circ} \mathrm{C}$ (Rōlov, 1935).

Leiukohad: Koobassaare järv (12. VII 1952, 10. VII 1956 - var. robustus Lillj., var. connectens Lillj.), Kalli järv (16. VIII 1952 - var. robustus), Parika järv (18. VI 1953 - var. robustus), Tänavjärv (7. VII 1953 - var. robustus, var. connectens).

Bythotrephes sp. (sabavars sirge, ilma B. cederstroemi’le omase kōverduseta, kuid muude tunnuste poolest erineb mōnevõrra Peipsi, Saadjärve ning Aheru B. longimanus'e eksemplaridest). Leiukohad: Kise järv (19. VI 1952, 15. VII 1957), Udriku Suurjärv (22. VII 1953, 12. VIII 1957), Ulemiste järv (18. VI 1957; Levanderi (1908) järgi Ulemistes $B$. cederstroemi var. connectens).

79. Leptodora kindti (F o k e). Väga tavaline, kuid veekogus väikesearvuline. Esineb järvede (ka väikeste ning madalate) pelagiaalis, samuti reas jõgedes (Emajões Lumberg, 1956; Narva jōes 21. VI 1922). Veekogu troofsuse, eriti aga humoossuse suhtes väga eurüplastiline. Leitud $\mathrm{pH}$ väärtuste $4->9,2$ juures. Oligosaproob.

Seni teada üle 150 leiukoha Eesti NSV mandrilt, Saare- ja Hiiumaalt.

\section{KIRJANDUS}

A u d ov a, A., 1923. Pühajärve plankton. Audova, A. ja Bekker, H. Andmeid Pühajärve uurimisest, 2. Tartu.

B org, F., 1935. Eine Cladocera als Parasit von Hydra. Zool. Anzeiger 110.

$\mathrm{Br}$ a u n, M., 1884. Physikalische und biologische Untersuchungen im westlichen Theile des finnischen Meerbusens. Archiv für die Naturkunde Liv-, Est- und Kurlands, Serie II, Band X, Lief. 1. Dorpat.

E k m a n, S., 1953. Zoogeography of the Sea. London.

Grube, A. E., 1853. Bemerkungen über die Phyllopoden nebst ihrer Gattungen und Arten. Archiv für Naturgeschichte, XIX Jahrg. Berlin.

$\mathrm{H}$ a be rm a n, H., 1956. I. V. Mitšurini ideede rakendamisest ökoloogilise zoogeograafia küsimustes. Eesti NSV TA Toimetised, Biol. seeria, V köide, nr. 1.

I s chreyt, G., 1942. Zur Kladozerenforschung im ostbaltischen Gebiet. Korrespondenzblatt des Naturforscher-Vereins zu Riga LXIV. Riga.

Kuptsch, P., 1926. Die Cladoceren der Umgegend von Riga. Archiv für Hydrobiologie XVIII.

Le piks a a r, J., 1932. Verzeichnis der Cladocera Eestis. Archiv für die Naturkunde Estlands, Serie II, Band XV, Lief. 1. Tartu.

1 Bythotrephes'te materjal on autoril põhjalikumalt analüüsimata. Ischr.

2 Riikoja (1944) mainib Saadjärves alamliiki Bythotrephes balticus Ischr. livonicus 
Lev ander, K. M., 1908. Die Zusammensetzung und die biologischen Verhältnisse des Planktons im Obersee. Schneider, G., Der Obersee bei Reval. Archiv für Biontologie. Berlin.

Levander, K. M., 1920. Beitrag zur Kenntnis des Planktons des Sees Wirzjerw. Mühlen, M. v. zur und Schneider, G., Der See Wirzjerw in Livland. Archiv für die Naturkunde des Ostbaltikums, Serie II, Band XIV, Lief. 1. Tartu.

Lill jeborg, W., 1900. Cladocera Sueciae. Nova Acta R. soc. Scient. Upsaliensis, Ser. III, vol. 19. Upsala.

Li nko, A., 1901. Beitrag zur Kenntnis der Phyllopodenfauna des europäischen Russlands. Тр. Имп. С.-Петербургского Общ. Естествоиспытателей. Отд. Зоол. и Физ., том XXXI, вып. 4, № 12.

L i p p m a a, T., 1935. Eesti geobotaanika pōhijooni. Acta et Comm. Univ. Tartuensis, A. 28,4 .

L u mberg, A., 1956. Emajōe planktonist. Loodusuurijate Seltsi Aastaraamat, 49. köide.

Mikelsaar, N., 1933. Andmeid mudakonna (Pelobates fuscus) levimisest Eestis. Auhinnatöö Tartu Olikoolis. Käsikiri Tartu Riikliku Olikooli Raamatukogus.

M ü hle n, M. v. zur, 1908. Die Raugeschen Seen. Sitzungsberichte der NaturforscherGesellschaft bei der Universität Jurjew XVII (3-4).

Po uls e n, E. M., 1928. Faunistische und biologische Untersuchungen über die Cladocerenfauna von Dänemark. Vidensk. Medd. Dansk. naturn. Foren, Bind 86. København.

R a m m ner, W., 1930. Phyllopoda. Die Tierwelt der Nord- und Ostsee, Lief. 18.

Ri ikoja, H., 1923. Tamula ja Vagula järve suvisest zooplanktonist. Andmeid Eesti ala jârvede uurimiseks, välja antud Loodusuurijate Seltsi poolt Tartu Ulikooli juures. Tartu.

Riikoja, H., 1925. Plankton-Tabelle für den August 1924 für den Finnischen Meerbusen. K. Frisch und H. Riikoja, Die Estnischen Terminfahrten in den Jahren 1923 und 1924. Tartu.

Ri i k o ja, H., 1928. Plankton-Tabellen der Estnischen Terminfahrten in den Jahren 1925 und 1920. K. Frisch und H. Rikkoja, Die Estnischen Terminfahrten in den Jahren 1925 und 1926. Tartu.

Ri i koja, H., 1929. Plankton-Tabellen der Estnischen Terminfahrten in den Jahren 1927 und 1928. K. Frisch und H. Riikoja, Die Estnischen Terminfahrten in den Jahren 1927 und 1928. Tartu.

R i ikoja. H., 1931. Plankton-Tabellen der Estnischen Terminfahrten in den Jahren 1929 und 1930. K. Frisch und H. Riikoja, Die Estnischen Terminfahrten in den Jahren 1929 und 1930. Tartu.

Rii k ołj a, H., 1934. Eesti järvede nimestik. Tartu Ulikooli juures oleva Loodusuurijate Seltsi aruanded XLI (1-2). Tartu.

Rylow, W. M., 1935. Das Zooplankton der Binnengewässer. Die Binnengewässer, Band XV. Stuttgart.

S epp, K., 1950. Emajōe Tähtvere vaatluspunkti ripaaltaimestikuvahelise organismide ühisuse koosseisust ja sesoonilisest dünaamikast. Diplomitöö Tartu Riiklikus Olikoolis. Käsikiri Tartu Riikliku Ulikooli zooloogia kateedris.

T a u be, E., 1911. Zur Kenntnis des Planktons der Kielkondschen Bucht auf Oesel. Die Biologische Station in Kielkond auf Oesel. Arbeiten des Naturforscher-Vereins zu Rıga, Heft 13. Riga.

V i n k e l, R., 1934. Vellavere Külajärve planktonist ja kaldafaunast. Eesti Loodus, nr. 5.

Thi ene mann, A., 1950. Verbreitungsgeschichte der Süsswassertierwelt Europas. Die Binnengewässer 18.

W e is e r, J., 1942. Holopedium gibberum auf der Böhmisch-Mährischen Anhöhe. Archiv für Hydrobiologie, Band XXXIX, Heft 2.

Wesenberg-Lund, C., 1939. Biologie der Süsswassertiere. Wien.

Бе н и н г А. Л., 1941. Кладоцера Қавказа. Тбилиси.

Г резе Б. С., 1933. Лимнологический очерк Валдайских озер и их предварительная рыбохозяйственная оценка. Изв. ВНИОРХ, том XVI.

М а н уйл о в а Е. Ф., 1949. Влияние дистрофности водоема на фауну Cladocera. Природные ресурсы, история и культура Карело-Финской ССР, вып. II.

Р ыл в В. М., 1940. Ветвистоусые ракообразные (Cladocera). Жизнь пресных вод, $1, \mathrm{AH}$ CCCP.

С а м с о н о в Н. А., 1906. Предварительный список животных организмов, собранных в озере Садъерв Лифл. губ. Прот. О-ва Естеств. при Имп. Юрьевском Универснтете XIV, вып. 2. 
С а м с о н в Н. А., 1908. К сведениям о планктоне оз. Шпанкау. Прот. О-ва Естеств. 'при Имп. Юрьевском Университете XVII.

С а м сон о в Н. А., 1912. Планктон Псковского водоема. Тр. Пром. Научн. Экспед. по изучению Псковского водоема. Псков.

С. а м соно в Н. А., 1913. Планктон Псковского водоема, II. Отдельный оттиск' из «Трудов Промыслово-Научн. Әкспедиции по изуч. Псковского водоемаъ, Псков.

Ш е н б ерг Н. Н., 1950. Состав и сезонная динамика зоопланктона средней части Финского залива по материалам, собранным в 1949 г. в окрестностях Рохунеэме. Дипломная работа в Тартуском гос. университете. Käsikiri TA Zooloogia ja Botaanika Instituudis.

Eesti NSV Teaduste Akadeemia

Zooloogia ja Botaanika Instituut

Saabus toimetusse

14. XI 1957

\section{ДАННЫЕ О ФАУНЕ ВЕТВИСТОУСЫХ РАЧКОВ (Cladocera) ЭСТОНИИ}

\section{А. X. Мяэметс}

\section{Резюме}

В статье приводятся в систематическом порядке виды ветвистоусых рачков, установленные для фауны Әстонской ССР, а также излагаются данные о распространении и экологии их в эстонских водоемах. Разработанный автором материал охватывает 978 проб, собранных из 348 разных водоемов республики (Балтийское море, озера, реки, мелкие водоемы разного типа) за 1909-1957 гг. Кроме того, при составлении сводки учтены и все ранее опубликованные данные и рукописи о фауне ветвистоусых рачков Әстонии. Вообще для фауны Әстонской ССР установлено 79 видов ветвистоусых рачков, 9 из которых - Limnosida frontosa, G. O. Sars, Daphnia magna Straus, Scapholeberis microcephala (Lillj.), Macrothix rosea (Jurine), Kurzia latissima (Kurz), Pleuroxus aduncus (Jurine), Chydorus latus G. O. Sars, Chydorus piger G. O. Sars н Anchistropus emerginatus G. O. Sars - являются новыми для фауны Әстонии.

Из 79 видов ветвистоусых рачков Әстонии 12 видов $(15,2 \%)$ - исключительно палеарктические, 27 видов $(34,2 \%)$ - голарктические и 40 (50,6\%) видов распространены, кроме Голарктики еще и в других регионах. Число бореальных видов - 14 $(17,7 \%)$ и бореотропических - $65(82,3 \%)$. Среди бореальных видов Limnosida frontosa, Ophryoxus gracilis и, по-видимому, Daphnia cristata, Scapholeberis microcephala, Drepanothrix dentata и Bythotrephes cederstroemi представляют собой элементы тайги. Элементами смешанных лесов можно считать следующие виды и подвиды: Daphnia cucullata, пелагическне подвиды Bosmina coregoni (coregoni - pяд) и Bythotrephes longimanus subsp. balticus (Ischr.). Последние два подвида - балтийские эндемики.

Вид Bosmina c. subsp. obtusirostris f. arctica, широко распространенный на верховых болотах Әстонии, можно считать арктическим элементом. Виды, являющиеся элементами тайги, распространены в основном в озерах с олиготрофными чертами на северо- и юго-востоке материковой части республики. Элементы смешанных лесов обитаІот в мезо- и эвтрофных озерах так называемой Высокой Әстонии.

Фауна ветвистоусых рачков Эстонии ближе всего к фауне Латвии, где, однако, еще более широкое распространение имеют элементы смешанных лесов. В общем фауна ветвистоусых рачков Әстонии характеризуется как фауна, свойственная смешанным лесам с присутствнем ряда видов тайги и немногими арктическими элементами.

На рис. 1 показано расположение водоемов Эстонин, исследованных в отношении Cladocera (1 - водоемы, исследованные автором; 2 - водоемы, исследованные другими авторами).

Ннститут зоологии и ботаники

Академии наук Эстонской ССР

Поступила в редакцию

14 XI 1957

\section{ZUR FAUNA DER WASSERFLÖHE (CLADOCERA) ESTLANDS}

\section{A. Mäemets}

\section{Zusammenfassung}

Der Artikel gibt ein systematisch angeordnetes Verzeichnis aller bisher in der Fauna Estlands festgestellten Wasserflöhe. Zugleich enthält der Artikel Angaben über die Ookologie und die geographische Verbreitung derselben in den estnischen Gewässern. Der Verfasser bearbeitet ein überaus reichliches Material, bestehend aus 978 Proben von 348 Gewässern (Ostsee, Binnenseen, Flüsse und verschiedene Kleingewässer), die 
während der Jahre 1909-1957 eingesammelt worden sind. Auch wird eine Menge früherer Literaturangaben in Betracht gezogen. Insgesamt konnten für Estland 79 Arten von Wasserflöhen festgestellt werden. Als neu für Estland werden 9 Arten angegeben: Limnosida frontosa G. O. Sars, Daphnia magna Straus, Scapholeberis microcephala (Lillj.), Macrothrix rosea (Jurine), Kurzia latissima (Kurz), Pleuroxus aduncus (Jurine), Chydorus latus G. O. Sars, Chydorus piger G. O Sars, Anchistropus emerginatus G. O. Sars.

Die Analyse des Bestandes der Wasserflöhefauna von Estland ergibt, dass von den 79 Arten $12(15,2 \%)$ nur in der Paläarktis, $27(34,2 \%)$ in der ganzen Holarktis und $40(50,6 \%)$ ausser der Holarktis auch in anderen Regionen verbreitet sind. Den klimatischen Zonen nach werden 14 Arten $(17,7 \%)$ als boreal und 65 Arten $(82,3 \%)$ als boreotropisch aufgefasst. Unter den borealen Arten können Limnosida frontosa. Uphryoxus gracilis und wahrscheinlich auch Daphnia cristata, Scapholeberis microcephaia, Drepanothrix dentata und Bythotrephis cederstroemi als Elemente der Taiga betrachtet werden.

$\mathrm{Zu}$ den Elementen der Mischwälderzone können Daphnia cucullata, die pelagischen Unterarten von Bosmina coregoni (coregoni-Reihe) und Bythotrephes longimanus subsp. balticus (Ischr.) (die zwei letzteren sind fürs Baltikum endemisch) gezählt werden. Eine Form der im allgemeinen borealen Art B. coregoni - B. C. subsp. obtusirostris f. arctica ist in den estnischen Hochmooren weit verbreitet und dürfte als ein arktisches Element betrachtet werden. Die Elemente der Taiga sind im allgemeinen in den oligotrophähnlichen Seen im Nordosten und Südosten der kontinentalen Teile Estlands, die Elemente der Mischwälderzone in meso- und eutrophen Seen von Hochestland verbreitet. Der Artenbestand der Wasserflöhefauna Estlands ist dem von Lettland überaus ähnlich, doch sind in Lettland die Elemente der Mischwälderzone zahlreicher.

Im allgemeinen kann die Fauna der Wasserflöhe Estlands als für die Mischwälderzone charakteristisch gelten; sie weist aber auch einige Elemente der Taiga und einzelne arktische Elemente auf.

Fig. 1 zeigt die in Hinsicht der Cladocera erforschten Gewässer (1 - vom Verfasser erforschte Gewässer; 2 - von früheren Autoren erforschte Gewässer).

Institut für Zoologie und Botanik der Akademie der Wissenschaften der Estnischen SSR
Eingegangen

am 14. Nov. 1957 